\title{
Health-related behaviours and hypertension prevention in Poland. An environmental study
}

\author{
Jana Krzysztoszek ${ }^{1}$ Ewelina Wierzejska², Anna Paczkowska ${ }^{1}$, Piotr Ratajczak ${ }^{1}$
}

${ }^{1}$ Department of Pharmacoeconomics and Social Pharmacy, Poznan University of Medical Sciences, Poznan, Poland

2Laboratory of International Health, Department of Preventive Medicine,

Poznan University of Medical Sciences, Poznan, Poland

Submitted: 30 June 2012

Accepted: 6 November 2012

Arch Med Sci 2013; 9, 2: 218-229

DOI: 10.5114/aoms.2013.34419

Copyright @ 2013 Termedia \& Banach

\section{Abstract}

Introduction: Primary and secondary prevention of hypertension is difficult and if the condition is not treated it may cause a number of dangerous complications. The objective of this study was to collect and systematize data on the health-related behaviours of Poles aiming at the prevention of hypertension in order to determine potential areas where primary health care could be improved. Material and methods: A group of 1018 participated in the study $(60 \%$ women and $40 \%$ men). The study was conducted in Poland in 2009 by means of an anonymous research questionnaire developed for survey use. The study involved people aged 30-50 years, who had not been diagnosed with hypertension, and who were under the care of a primary care physician.

Results: Over $35 \%$ of respondents in the potential risk group do not measure blood pressure at all, and just over $10 \%$ perform cholesterol and blood glucose level tests more often than once a year. Individuals who pay most attention to prevention in the form of physical activity are women, more often young (67\% of people under 35$)$, unmarried (52\%), mostly with secondary or higher education. Moreover, one third of the women surveyed (32.4\%) and almost half of men $(48.4 \%)$ stated that they smoke cigarettes, and in most men $(66.3 \%)$ the amount of alcohol taken in one serving exceeded the pressor threshold (>20 g). Conclusions: Desirable health-promoting actions such as stress reduction are effective but actions such as consuming alcohol and eating fats are unsatisfactory and require intensive public education.

Key words: hypertension, prevention, survey, preventive measures.

\section{Introduction}

Chronic diseases are becoming a growing challenge for modern medical care in developed societies. Most of them are associated with disorders in the function of the cardiovascular system. Big-city dwellers are primarily exposed to the occurrence of these diseases.

According to a study conducted in 2006 nearly $42 \%$ of the population aged between 35 and 64 years suffered from hypertension (HTN) in Poland and the incidence of the disease increased with age, reaching over $70 \%$ of the population of older people [1]. With no disease-specific symptoms, diagnosis of hypertension becomes particularly difficult to make. If not treated, the condition may lead to a number of danger-

\author{
Corresponding author: \\ Jana Krzysztoszek MD, PhD \\ Department \\ of Pharmacoeconomics \\ and Social Pharmacy \\ Poznan University \\ of Medical Sciences \\ 79 Dabrowskiego St \\ 60-529 Poznan, Poland \\ Phone: +48 791979575 \\ E-mail: metelska@ump.edu.pl
}


ous complications: atherosclerosis, damage of coronary arteries, heart, kidneys and visual system, and in consequence even to death [2, 3].

Pharmacotherapy of this disease, which is only a symptomatic treatment, is a long and costly process for both the patient and the healthcare system. Therefore, lifestyle modification - involving the introduction of appropriate health-promoting behaviours concerning its various aspects, i.e. diet, regular physical activity, overcoming addictions or finding a way to manage stress - is the only promising way to combat this disease as well as the rising costs of hypertension treatment in industrialized countries [4]. Literature reports indicate that a fundamental generational change in health behaviour patterns is currently taking place [5]. However, a study of 2008 [6] evaluating the knowledge of Poles on the prevention of HTN demonstrated that although the knowledge of the patients surveyed was sufficient, it was believed not to be put into practice. These conclusions contributed to undertaking this further research aiming to evaluate the current attitude of patients to HTN prevention.

The purpose of this study was to collect and systematize data on the health-promoting behaviours of Poles towards prevention of HTN.

\section{Material and methods}

The study was conducted on 1018 people $(60 \%$, $n=611$ women and 40\%, $n=407$ men). Randomquota sampling was used within the sampling frame of the list of general practitioner clinics that have a contract with the NFZ (National Health Fund) to provide primary care. Every tenth clinic on the list was contacted to obtain GP's consent for the survey study to be carried out in their clinics among the patients under their care and to inform them of the aims and assumptions of the study. Having obtained the consent, a surveyor conducted a oneday survey (within the time limit set by the GP) among the patients who had appointments with the GP on the given day, and who also met the predetermined criteria qualifying them for the survey and agreed to take part in it. Each time a potential subject was advised of the aim of the study, of the institution conducting the research project, of the way the data to be collected would be used, as well as of the voluntary and anonymous character of participating in the survey. With the explicit consent of the potential subject, the surveyor made the research questionnaire available to the patient. Patients completed the questionnaire on their own.

The criteria for including a patient in the study were as follows:

- age between 30 and 50 years,

- no HTN diagnosis,

- being under GP's care,
- inhabiting the city of Poznan (the third largest city in Poland with a population of approx. 560,000) [7],

- knowing consent to participate in the study.

The study was conducted within a period from September to December 2009, by means of a research questionnaire prepared specially for survey use.

The questionnaire was prepared in accordance with the concept of Kornhauser and Sheatlsey [8]. Twenty people aged 30-50 years, who were not diagnosed with hypertension and who were not related to the field of medicine, participated in the pilot study.

The questionnaire covered multiple areas. The content-related part of the questionnaire consisted of 24 questions divided according to their subject matter into 6 logical batteries of questions with the maximum of 6 questions each. Most of the questions were categorized multiple-choice questions describing health-promoting behaviours of primary care patients within the following batteries: 1 . General prevention of hypertension; 2 . Prophylaxis to reduce substance use; 3 . Nutritional prevention; 4. Prophylaxis in the form of physical activity; 5 . Pharmacological prophylaxis; 6. Evaluation and awareness. The questions of the first battery asked patients how often they had their blood pressure measured (q. 1), and their blood cholesterol and glucose levels tested (q. 2), how they managed their body weight (q. 3), how they coped with stress (q. 6) and why they had doctor's appointments within the last year (q. 24). The second battery contained questions about smoking tobacco (q. 4) and drinking alcohol (q. 7, 8 and 9). The third battery contained diet-related questions. Respondents were asked about their behaviours connected with the consumption of salt (q. 5), potassium and magnesium (q. 14), and different kinds of fats (q. 15), as well as about the products they ate most often (q. 18), their consumption of foods lowering blood cholesterol levels (q. 20) and consumption of sweets (q. 23). The fourth battery determined the respondents' frequency of undertaking regular physical exercise (q. 10), the kinds of sports and recreational physical activities they did most often (q. 11), and the frequency of making moderate physical effort (q. 13). The fifth battery comprised questions connected with pharmacotherapy used by patients, including long-term use of painkillers and/or contraceptives (q. 12), as well as preparations or medicines taken prophylactically (q. 21). The sixth battery contained questions asking the respondents to evaluate their lifestyle (q. 16) and health (q. 17), and also to evaluate and compare pharmacological and non-pharmacological therapy effectiveness in selected areas (q. 22). In addition, it included a question testing the respondents' knowledge of HTN risk factors (q. 19).

Questions 1, 2, 3, 5, 7, 10, 13, 21, 23 and 24 were categorized multiple-choice questions. Contingency 
questions 7, 21 and 24 led sequentially to more specific questions. Questions 4, 6, 8, 9, 12, 14, 15 and 20 were dichotomous questions. The questionnaire also contained semi-open questions (q. 16, 17), semi-open questions with a verbal scale (q. 22), and multiple choice close-ended questions with a number of options to choose from and a possibility to choose more than one option (q. 11, 18, 19), which were explicitly described as such. Moreover, in questions 11, 19, 21 and 24 it was also possible to add one's own answer that had not been included in the list of options.

At the end of the questionnaire there was a separate section with personal data questions asking about social and demographic data. Demographics were obtained by means of 8 questions about age, sex, marital status, education, number of children, family history of HTN, height and weight. It allowed the researchers to determine a respondent's genetic, demographic and risk-factor predisposition to HTN in the future, that is, whether a respondent is or is not in the high-risk group.

\section{Ethical approval}

Patients, having been fully informed of the purpose of the study and the intended use of results, knowingly consented to participation in the scientific research. The study was conducted in compliance with ethical requirements and international environmental research standards with the consent of the relevant committee (Bioethics Committee).

\section{Statistical analysis}

The results obtained were subjected to cluster analysis (two-level clustering, ANOVA test, contingency tables showing the percentage composition of 3 selected groups sex, body mass index (BMI), age, education, marital status), which was believed to be the most suitable method for determining whether any specific prevention patterns exist. To that end, Statistica 8 PL package and PASW Statistics 18 were used. Quantitative data were characterized by determining the subgroup size, percentage, mean value for groups with standard deviation, and maximum and minimum values. Data on nominal capacity were described by means of size and proportion. In order to compare different categories of prevention with one another and to perform statistical operations aimed at selecting specific groups, answers were converted by the subjects on the rate scale for each category of prevention. The score was expressed as a percentage according to the principle that the higher the number, the greater the emphasis on the prevention aspect. Body mass index of the respondents was calculated on the basis of weight and height data obtained by means of demographic questions.

\section{Results}

The analysis of the data showed that the average age was 38 (women were slightly younger than men $-37.4 \pm 6.3$ to $39.4 \pm 6.3$ ) (Table I). The largest group consisted of married people (over $60 \%$ ); single people constituted nearly $1 / 4$, with $14.1 \%$ of women and $11.5 \%$ of men without a partner. Regardless of sex, most people had tertiary or secondary education. No significant asymmetry in the distribution of independent variables (age, education, sex) allowed for a positive evaluation of the selection of the study group.

A BMI analysis of the individuals surveyed showed that the majority (68\%) are in the normal body weight category. However, quite a large proportion of men (44.2\%) were in the "overweight" category, in which the risk of death due to the development of a cardiovascular disease is slightly increased compared to those with normal body weight (Table I).

\section{General prevention of hypertension}

The vast majority of respondents did not measure blood pressure regularly (Table I). The structure of the frequency of blood pressure measurements in relation to sex was similar, with a slightly higher percentage of measuring women. Analysis of the cholesterol and blood glucose testing frequency was used to estimate the parameters describing the state of the circulatory system and allowed estimation of the risk of developing a cardiovascular disease. The vast majority of respondents did not carry out such tests. The vast majority of female respondents and more than half of male respondents attempted to keep their body weight in the normal range (Table I).

\section{Prophylaxis to reduce substance use}

One third of the women surveyed (32.4\%) and almost half of men (48.4\%) stated that they smoke cigarettes (Table II). Alcohol consumption behaviours look even less favourable in the assessment. The results indicate the predominance of spirits consumption over that of beer and wine. It should be stressed that for the vast majority of male respondents (66.3\%) the amount of alcohol taken in one serving exceeded the pressor threshold (> $20 \mathrm{~g}$ ). Considering the frequency of alcohol consumption (prevalence of 2-4 times a week), and the nature and quantity of consumption, it is difficult to speak of subjects' health-promoting behaviours. For women the situation is slightly better, because they rarely exceed the pressor threshold; however, they consume spirits more often, which makes the current situation unsatisfactory and requiring intensification of educational activities in this scope. 
Table I. Socio-demographic data of respondents, BMI and measurement of blood pressure, cholesterol and glucose levels and maintenance of normal body weight

\begin{tabular}{|c|c|c|c|c|}
\hline \multirow[t]{2}{*}{ Parameter } & \multicolumn{2}{|c|}{ Women $(n=611)$} & \multicolumn{2}{|c|}{ Men $(n=407)$} \\
\hline & Frequency & Percentage & Frequency & Percentage \\
\hline \multicolumn{5}{|l|}{ Age [years] } \\
\hline Mean and SD & \multicolumn{2}{|c|}{$37.4 \pm 6.3$} & \multicolumn{2}{|c|}{$39.4 \pm 6.3$} \\
\hline $30-35$ & 260 & 42.6 & 114 & 28.0 \\
\hline $36-40$ & 146 & 23.9 & 102 & 25.1 \\
\hline $41-45$ & 92 & 15.1 & 84 & 20.6 \\
\hline $46-50$ & 113 & 18.4 & 107 & 26.3 \\
\hline \multicolumn{5}{|l|}{ BMI $\left[\mathrm{kg} / \mathrm{m}^{2}\right]$} \\
\hline Mean and SD & \multicolumn{2}{|c|}{$22.7 \pm 3.3$} & \multicolumn{2}{|c|}{$25.1 \pm 2.9$} \\
\hline Min and $\max$ & 15.6 & 59.5 & 18.5 & 47 \\
\hline$<18.50$ & 33 & 5.4 & & \\
\hline $18.50-24.99$ & 480 & 78.6 & 212 & 52.1 \\
\hline $25.00-29.99$ & 83 & 13.6 & 180 & 44.2 \\
\hline $30.00-34.99$ & 11 & 1.8 & 12 & 2.9 \\
\hline $35.00-39.99$ & 3 & 0.5 & 1 & 0.2 \\
\hline$>40.00$ & 1 & 0.2 & 2 & 0.5 \\
\hline \multicolumn{5}{|l|}{ Blood pressure measurement } \\
\hline No & 206 & 33.7 & 163 & 40.0 \\
\hline Several times a year & 65 & 10.6 & 45 & 11.1 \\
\hline 1-2 times per month & 142 & 23.2 & 82 & 20.1 \\
\hline $1-2$ times per week & 198 & 32.4 & 117 & 28.7 \\
\hline \multicolumn{5}{|c|}{ Measurement of cholesterol and glucose levels } \\
\hline No & 316 & 51.7 & 252 & 61.9 \\
\hline Less than once a year & 103 & 16.9 & 56 & 13.8 \\
\hline Once a year & 119 & 19.5 & 51 & 12.5 \\
\hline More than once a year & 73 & 11.9 & 48 & 11.8 \\
\hline Total & 611 & 100.0 & 407 & 100.0 \\
\hline \multicolumn{5}{|c|}{ Normal body weight maintenance } \\
\hline Care for normal body weight & 462 & 75.6 & 231 & 56.8 \\
\hline
\end{tabular}

\section{Nutritional prevention}

Further analysis of the respondents' behaviours demonstrated that men's diet contains more calories and less fibre because men eat far less fruit and vegetables. The key point is the fact that animal fats predominate in the diet of both sexes, but it is also worth noting that $43.4 \%$ of women and $26.3 \%$ of men eat various kinds of cholesterol-lowering foods (e.g. margarine containing plant sterols). Furthermore, women eat considerably more sweets than men.

Another important element of HTN prevention is to reduce the amount of salt in the diet, which was a behaviour reported by $1 / 3$. More than half of the respondents indicated that they try not to over- use it (Table II). The result obtained indicates that only a small part of Polish society (on average approximately $15 \%$ ) does not attribute any importance to this, which should be considered to be a positive phenomenon.

\section{Prophylaxis in the form of physical activity}

It may be concluded from Table III and Figure 1 that most Poles rarely take physical exercise. Only $14.2 \%$ of women and $18.4 \%$ of men exercise regularly, at least twice a week. The most popular activities undertaken by the respondents include going for walks (70\%) and cycling (almost 60\%). Taking physical activity into account, most respondents assessed their own lifestyle as moderately active, 
Table II. Cigarette smoking, alcohol consumption and essential elements of the diet from the point of view of HTN prevention

\begin{tabular}{|c|c|c|c|c|}
\hline \multirow[t]{2}{*}{ Parameter } & \multicolumn{2}{|c|}{ Women } & \multicolumn{2}{|c|}{ Men } \\
\hline & Frequency & Percentage & Frequency & Percentage \\
\hline Cigarette smoking & 198 & 32.4 & 197 & 48.4 \\
\hline \multicolumn{5}{|l|}{ Alcohol consumption } \\
\hline No & 90 & 14.7 & 38 & 9.3 \\
\hline Occasionally & 258 & 42.2 & 90 & 22.1 \\
\hline 2-4 times a month & 184 & 30.1 & 124 & 30.5 \\
\hline 2-4 times a week & 76 & 12.4 & 128 & 31.4 \\
\hline Daily & 3 & 0.5 & 27 & 6.6 \\
\hline \multicolumn{5}{|l|}{ Alcohol units on a single occasion } \\
\hline$<20 \mathrm{~g}$ & 369 & 60.4 & 137 & 33.7 \\
\hline$>20 \mathrm{~g}$ & 242 & 39.6 & 270 & 66.3 \\
\hline \multicolumn{5}{|l|}{ Type of alcohol } \\
\hline Beer, wine & 221 & 36.2 & 184 & 45.2 \\
\hline Spirits & 390 & 63.8 & 223 & 54.8 \\
\hline \multicolumn{5}{|l|}{ Salt in the diet } \\
\hline Limiting the amount of salt & 321 & 52.5 & 213 & 52.3 \\
\hline Avoiding salty foods & 216 & 35.4 & 114 & 28.0 \\
\hline \multicolumn{5}{|l|}{ Potassium and magnesium } \\
\hline A diet rich in potassium and magnesium & 537 & 87.9 & 291 & 71.5 \\
\hline \multicolumn{5}{|l|}{ Type of fat consumed } \\
\hline Vegetable & 272 & 44.5 & 137 & 33.7 \\
\hline Animal & 339 & 55.5 & 270 & 66.3 \\
\hline Cholesterol-lowering products & 265 & 43.4 & 107 & 26.3 \\
\hline \multicolumn{5}{|l|}{ Consumption of sweets } \\
\hline No & 51 & 8.3 & 36 & 8.8 \\
\hline Little & 300 & 49.1 & 237 & 58.2 \\
\hline Much & 260 & 42.6 & 134 & 32.9 \\
\hline Total & 611 & 100.0 & 407 & 100.0 \\
\hline
\end{tabular}

with a predominance of moderate exercise performed 4-6 times a week. Irrespective of this, most respondents (of both sexes) assessed their health as satisfactory. The study also shows that over $75 \%$ of patients manage to cope with chronic stress accompanying their daily lives, which greatly reduces the risk of HTN development in these patients.

\section{Pharmacological prophylaxis}

Thirty-eight percent of women take contraceptives/painkillers and $11.5 \%$ of men take painkillers on a long-term basis. Approximately $30 \%$ of respondents take medications prophylactically, most often choosing dietary minerals, herbal preparations and products containing $\omega-3$ fatty acids (Table IV). At the same time it should be noted that although in the opinion of patients nonpharmacological therapy is safer, a therapy involving the use of drugs is considered to be more effective (Figure 2). In terms of the frequency of visits to various doctors, the respondents most often go to the doctor for preventive examinations, and secondly because of a sudden illness. Less than $7 \%$ of respondents see a doctor for HTN prophylaxis (Table IV).

The results in the prophylaxis scales with regard to the allocation criteria sex, education, BMI levels and health status assessment revealed slight differences in the profiles of different groups of people. Prevention in the form of physical activity was 
Table III. Physical activity and self-assessment of respondents on their lifestyle and state of health, stress management and moderate physical activity

\begin{tabular}{|c|c|c|c|c|}
\hline \multirow[t]{2}{*}{ Parameter } & \multicolumn{2}{|c|}{ Women } & \multicolumn{2}{|c|}{ Men } \\
\hline & Frequency & Percentage & Frequency & Percentage \\
\hline \multicolumn{5}{|l|}{ Physical activity } \\
\hline None & 63 & 10.3 & 49 & 12.0 \\
\hline Rarely & 279 & 45.7 & 181 & 44.5 \\
\hline Sometimes & 182 & 29.8 & 102 & 25.1 \\
\hline Regularly & 87 & 14.2 & 75 & 18.4 \\
\hline \multicolumn{5}{|l|}{ Lifestyle assessment } \\
\hline Passive & 102 & 16.7 & 95 & 23.3 \\
\hline Medium-active & 425 & 69.6 & 231 & 56.8 \\
\hline Active & 84 & 13.7 & 81 & 19.9 \\
\hline \multicolumn{5}{|l|}{ State of health assessment } \\
\hline Bad & 10 & 1.6 & 3 & 0.7 \\
\hline Unsatisfactory & 57 & 9.3 & 40 & 9.8 \\
\hline Satisfactory & 327 & 53.5 & 234 & 57.5 \\
\hline Good & 217 & 35.5 & 130 & 31.9 \\
\hline \multicolumn{5}{|l|}{ Effective stress management } \\
\hline $\begin{array}{l}\text { Lack of stress or having an effective } \\
\text { method of stress management }\end{array}$ & 465 & 76.1 & 320 & 78.6 \\
\hline \multicolumn{5}{|l|}{ Moderate physical activity } \\
\hline Never & - & - & 5 & 1.2 \\
\hline Several times a year & 11 & 1.8 & 24 & 5.9 \\
\hline 4-6 times a week & 33 & 5.4 & 27 & 6.6 \\
\hline Once a week & 70 & 11.5 & 95 & 23.3 \\
\hline 2-3 times a week & 210 & 34.4 & 105 & 25.8 \\
\hline 4-6 times a week & 287 & 47.0 & 151 & 37.1 \\
\hline Total & 611 & 100.0 & 407 & 100.0 \\
\hline
\end{tabular}

emphasised in all scales. The only interesting result obtained in these scales was increased prevention within the scope of reduction of substances used by people with a BMI above $30 \mathrm{~kg} / \mathrm{m}^{2}$.

In an attempt to answer the question whether there are any specific patterns of preventive health care, cluster analysis was performed, which singled out three groups with the following prevention profiles and characteristics: group 1 - little care for prevention; 2 - care for prophylaxis in the form of physical activity; and 3 - increased concern for substance use reduction, as well as nutritional and pharmacological prophylaxis (Figure 3).

The percentages of individuals within a particular cluster with respect to qualitative variables are presented in Table V. Despite attempts to identify a specific prevention pattern no other regularity was confirmed other than the one that prevention in the form of physical activity is the most common one whereas pharmacological prevention is the least used. Individuals who pay most attention to prevention in the form of physical activity are women, more often young ( $67 \%$ of people under 35), unmarried (52\%), mostly with second-

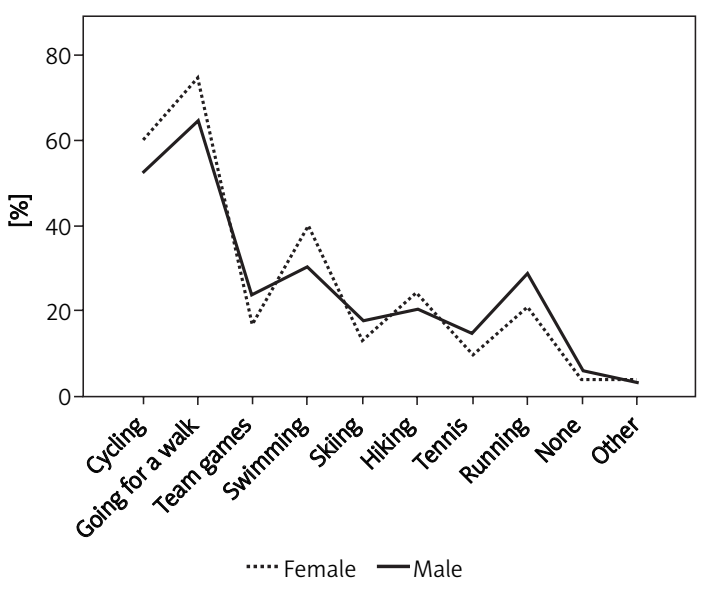

Figure 1. Sport and recreational activities undertaken by the respondents in free time 
Table IV. Respondents' reasons for doctor visits over the last year

\begin{tabular}{|c|c|c|c|c|c|c|c|}
\hline \multirow[t]{2}{*}{ Parameter } & \multicolumn{2}{|c|}{ From response } & \multirow{2}{*}{$\begin{array}{l}\text { Percentage of the } \\
\text { persons being } \\
\text { surveyed } \\
\text { se }\end{array}$} & \multicolumn{2}{|c|}{ Women } & \multicolumn{2}{|c|}{ Men } \\
\hline & $n$ & Percentage & & $n$ & Percentage & $n$ & Percentage \\
\hline \multicolumn{8}{|l|}{ Reason for a visit } \\
\hline No visits & 141 & 11.4 & 13.9 & 75 & 12.3 & 66 & 16.3 \\
\hline Sudden illness & 361 & 29.3 & 35.5 & 194 & 31.8 & 167 & 41.2 \\
\hline Chronic disease & 117 & 9.5 & 11.5 & 65 & 10.6 & 52 & 12.8 \\
\hline Prophylaxis & 614 & 49.8 & 60.4 & 411 & 67.3 & 203 & 50.1 \\
\hline \multicolumn{8}{|l|}{ If prevention, then } \\
\hline $\begin{array}{l}\text { HTN prevention } \\
\text { (GP, cardiologist) }\end{array}$ & 70 & 6.7 & 11.3 & 22 & 5.3 & 48 & 23.4 \\
\hline Ophthalmologist & 239 & 22.8 & 38.7 & 169 & 41.0 & 70 & 34.1 \\
\hline Gynaecologist & 295 & 28.1 & 47.8 & 287 & 69.7 & 8 & 3.9 \\
\hline Dentist & 366 & 34.9 & 59.3 & 233 & 56.6 & 133 & 64.9 \\
\hline Other & 80 & 7.6 & 13.0 & 60 & 14.6 & 20 & 9.8 \\
\hline \multicolumn{8}{|l|}{ Medications used prophylactically } \\
\hline Microelements & 196 & 29.6 & 65.1 & 125 & 63.1 & 71 & 68.9 \\
\hline Slimming pills & 32 & 4.8 & 10.6 & 27 & 13.6 & 5 & 4.9 \\
\hline $\begin{array}{l}\text { Preparations containing } \\
\text { red wine extract }\end{array}$ & 20 & 3.0 & 6.6 & 18 & 9.1 & 2 & 1.9 \\
\hline $\begin{array}{l}\text { Preparations containing } \\
\text { coenzyme Q10 }\end{array}$ & 78 & 11.8 & 25.9 & 71 & 35.9 & 7 & 6.8 \\
\hline $\begin{array}{l}\text { Preparations containing } \\
\text { omega } 3 \text { fatty acids }\end{array}$ & 115 & 17.3 & 38.2 & 77 & 38.9 & 38 & 36.9 \\
\hline Cholesterol-lowering preparations & 49 & 7.4 & 16.3 & 29 & 14.6 & 20 & 19.4 \\
\hline Herbal preparations & 118 & 17.8 & 39.2 & 86 & 43.4 & 32 & 31.1 \\
\hline Anti-infarct drugs & 32 & 4.8 & 10.6 & 14 & 7.1 & 18 & 17.5 \\
\hline Other & 23 & 3.5 & 7.6 & 16 & 8.1 & 7 & 6.8 \\
\hline Total & 663 & 100.0 & 220.3 & 198 & & 103 & \\
\hline
\end{tabular}

ary $(33 \%)$ or higher (29\%) education, most of them with a BMI below $18.5 \mathrm{~kg} / \mathrm{m}^{2}$. Men represent a homogeneous group (all in cluster 1 ) regularly

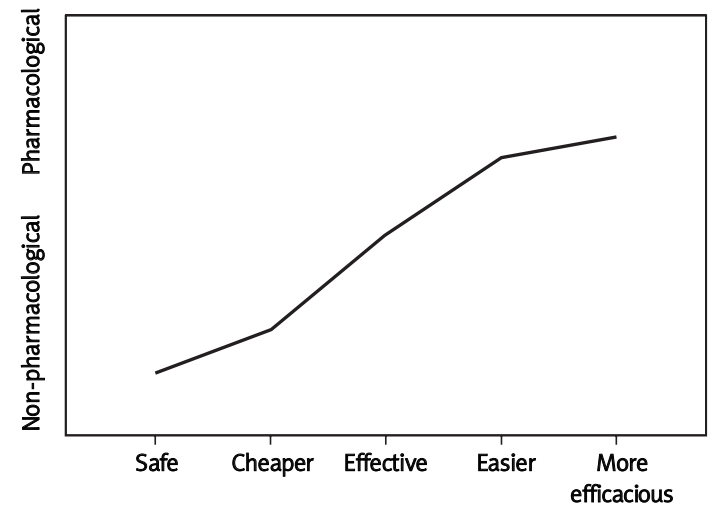

Figure 2. Evaluation of non-pharmacological and pharmacological therapy obtaining lower scores than women on all scales of prevention.

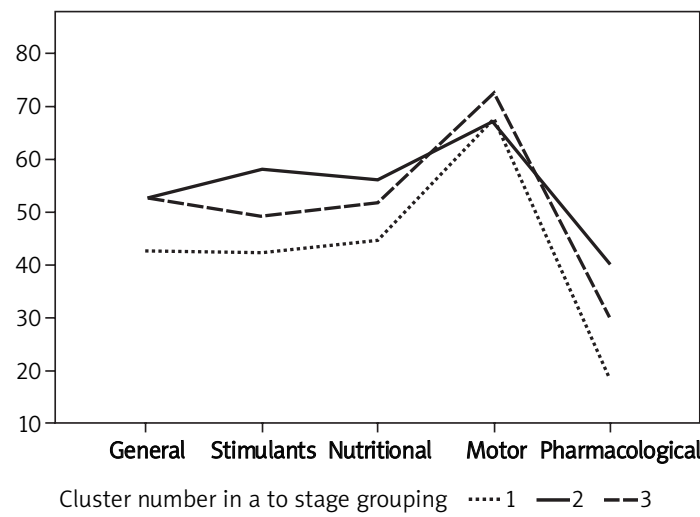

Figure 3. Prophylaxis profiles in three singled-out groups 
Table V. Percentage composition of singled-out clusters with reference to sex, BMI, education, age, marital status

\begin{tabular}{|c|c|c|c|c|c|}
\hline \multirow[t]{2}{*}{ Cross table } & & \multicolumn{3}{|c|}{ Cluster number in the two-stage grouping } & \multirow[t]{2}{*}{ Total } \\
\hline & & 1 & 2 & 3 & \\
\hline \multicolumn{6}{|l|}{$\operatorname{Sex}^{*}$} \\
\hline \multirow[t]{2}{*}{ Female } & $n$ & 1 & 330 & 280 & 611 \\
\hline & $\%$ & 0.2 & 54.0 & 45.8 & 100 \\
\hline \multirow[t]{2}{*}{ Male } & $n$ & 407 & 0 & 0 & 407 \\
\hline & $\%$ & 100 & 0.0 & 0.0 & 100 \\
\hline \multicolumn{6}{|c|}{ BMIs2 $^{*}\left[\mathrm{~kg} / \mathrm{m}^{2}\right]$} \\
\hline \multirow[t]{2}{*}{$<18.50$} & $n$ & 0 & 6 & 27 & 33 \\
\hline & $\%$ & 0.0 & 18.2 & 81.8 & 100 \\
\hline \multirow[t]{2}{*}{$18.50-24.99$} & $n$ & 212 & 246 & 234 & 692 \\
\hline & $\%$ & 30.6 & 35.5 & 33.8 & 100 \\
\hline \multirow[t]{2}{*}{$25.00-29.99$} & $n$ & 180 & 65 & 18 & 263 \\
\hline & $\%$ & 68.4 & 24.7 & 6.8 & 100.0 \\
\hline \multirow[t]{2}{*}{$\geq 30$} & $n$ & 16 & 13 & 1 & 30 \\
\hline & $\%$ & 53.3 & 43.3 & 3.3 & 100.0 \\
\hline \multicolumn{6}{|l|}{ Education* } \\
\hline \multirow[t]{2}{*}{ Primary } & $n$ & 5 & 7 & 2 & 14 \\
\hline & $\%$ & 35.7 & 50.0 & 14.3 & 100.0 \\
\hline \multirow[t]{2}{*}{ Vocational } & $n$ & 73 & 45 & 2 & 120 \\
\hline & $\%$ & 60.8 & 37.5 & 1.7 & 100.0 \\
\hline \multirow[t]{2}{*}{ Secondary } & $n$ & 148 & 132 & 139 & 419 \\
\hline & $\%$ & 35.3 & 31.5 & 33.2 & 100.0 \\
\hline \multirow[t]{2}{*}{ Higher } & $n$ & 182 & 146 & 137 & 465 \\
\hline & $\%$ & 39.1 & 31.4 & 29.5 & 100.0 \\
\hline \multicolumn{6}{|c|}{ Age (divided) ${ }^{\star}$ [years] } \\
\hline \multirow[t]{2}{*}{$30-35$} & $n$ & 114 & 8 & 252 & 374 \\
\hline & $\%$ & 30.5 & 2.1 & 67.4 & 100.0 \\
\hline \multirow[t]{2}{*}{$36-40$} & $n$ & 103 & 120 & 25 & 248 \\
\hline & $\%$ & 41.5 & 48.4 & 10.1 & 100.0 \\
\hline \multirow[t]{2}{*}{$41-45$} & $n$ & 84 & 92 & 0 & 176 \\
\hline & $\%$ & 47.7 & 52.3 & 0.0 & 100.0 \\
\hline \multirow[t]{2}{*}{$46-50$} & $n$ & 107 & 110 & 3 & 220 \\
\hline & $\%$ & 48.6 & 50.0 & 1.4 & 100.0 \\
\hline \multicolumn{6}{|l|}{ Marital status ${ }^{*}$} \\
\hline \multirow[t]{2}{*}{ Unmarried } & $n$ & 100 & 16 & 130 & 246 \\
\hline & $\%$ & 40.7 & 6.5 & 52.8 & 100.0 \\
\hline \multirow[t]{2}{*}{ Married } & $n$ & 261 & 236 & 142 & 639 \\
\hline & $\%$ & 40.8 & 36.9 & 22.2 & 100.0 \\
\hline \multirow[t]{2}{*}{ Single } & $n$ & 47 & 78 & 8 & 133 \\
\hline & $\%$ & 35.3 & 58.6 & 6.0 & 100.0 \\
\hline Total & $n$ & 408 & 330 & 280 & 1018 \\
\hline & $\%$ & 40.1 & 32.4 & 27.5 & 100.0 \\
\hline
\end{tabular}




\section{Discussion}

\section{General prevention of hypertension}

In the face of the increasing incidence of modern-age diseases, including hypertension, which underlie the excessive mortality of modern societies, there is a growing need to implement effective prevention programmes [9].

In 2004 one in four (27.0\%) 40-year-old Poles and almost one in two (46.5\%) 50-year-old Poles were tested positive for high blood pressure, and generally high levels (above $200 \mathrm{mg} \%$ ) of total cholesterol were noted in one in three people (38.4\%) undergoing these tests [7]. With regard to the CSO data [7] that one in ten adult Poles has never had their blood pressure tested and only every second adult Pole has had their cholesterol level tested at least once in a lifetime, it appears to be advisable that people of working age should be obliged to perform periodic prevention examinations including lipid and glucose level tests as well as blood pressure measurement.

In our study, the vast majority of female respondents $(75.6 \%)$ and more than half of male respondents $(56.8 \%)$ stated that they care for their appropriate body weight. Given the fact that $80 \%$ of HTN cases in Poland are associated with increased body weight [9], it is undoubtedly a positive phenomenon. The study by Mastalerz-Migas et al. [10] confirmed this fact, although only partly because widespread overweight (26\% F (female) and $70 \% \mathrm{M}$ (male)) and obesity ( $5 \%$ female and $12 \%$ male) were observed in the study. The same study also showed a serious lack of awareness of this fact among respondents ( $40 \%$ male and $7 \%$ female) [10]. The results obtained in our study show that women see a doctor more often than men $(67.3 \%$ female, 50.1\% male) in order to perform preventive examinations, which is also indirectly confirmed by the studies of Mardarowicz et al. of 2008 [9] showing that the frequency of visiting a doctor for prophylactic examinations is smaller in the country $(60 \%$ female and $54 \%$ male) than in the city (62\% female and 55\% male).

Taking into account the responses obtained in this study and the results of previous studies [6] it should be noted that the knowledge possessed by the respondents is not translated into practice. It does not significantly influence a change in healthrelated behaviours because patients are not motivated towards it [11]. Having even very extensive knowledge is not sufficient, in the absence of willingness and determination [10]. Therefore, it should be considered necessary to design and implement social campaigns which would facilitate improvement of the effectiveness of preventive measures, and increase awareness of the positive influence of prevention on health.

\section{Prophylaxis to reduce substance use}

WHO statistics showed that Poland has got one of the highest smoking prevalence rates in Europe [12] and in the world [13]. In the studies carried out in all European countries in 2002 in the age group 20 to 64 , it was shown that in Poland $46 \%$ of men and $31 \%$ of women [14] smoke cigarettes. Our study provided similar results $-48.4 \%$ and $32.4 \%$ respectively. This puts Poland in the 6th place in Europe among men and in the $7^{\text {th }}$ among women [14]. In comparison to, for example, the United Kingdom, where $25 \%$ of men and $23 \%$ of women [15] smoke cigarettes, and to the percentage of smokers in the general German (30\%) and European (32\%) [16] populations, current results on the prevalence of smoking in Poland are still high.

Alcohol consumption in Poland is, first and foremost, a problem of excessive drinking of spirits that are preferred over all other forms of alcohol, which was also confirmed by the results of our study. According to the CSO data (2007), 100\% alcohol consumption per capita in Poland increased over the past 10 years by more than 2 I (from 7.02 I to $9.21 \mathrm{l}$ ) and the latest data indicate that the consumption amounts to 10.5 I of $100 \%$ alcohol per inhabitant per year [7]. More than half of alcohol in Poland is consumed by people within the age of 25 to 44 years, mainly men in the period of greatest professional activity [7]. In our study it was also men who most often crossed the pressor threshold. According to the data of the International Wine and Spirits, in 2006 Europeans drank 79 billion I of alcohol, i.e. 101.25 I per person. People in the U.S. in the same period consumed 98.7 I of liquors per capita, while in the countries of Asia and the Pacific region, this rate was only 22.1 I [17].

With regard to the frequency of alcohol consumption, the results of our study may be considered consistent with the results of a survey (2009) conducted in all EU countries on the group of respondents over 15 years of age [18], because the difference in the age of the respondents could lower a result in a Euro poll. That result indicates that $19 \%$ of Poles drink alcohol 2-3 times a week. Considering the fact that $23 \%$ of EU citizens use alcohol 2-3 times a week, 9\% 4-5 times a week and as many as $14 \%$ of EU citizens admitted that they drink on a daily basis, whereas in Poland only $1 \%$ of people [18] drink every day (in our study $0.5 \%$ of women and $6.6 \%$ of men), the results obtained demonstrate that we are far below the EU average. On the whole, while considering the problem of alcohol consumption in Poland special attention should be paid not only to the structure of drinks consumed, but also to socially acceptable drinking patterns. They consist in a one-time excessive consumption that almost always leads to intoxication, which is also confirmed by our results. It is currently 
estimated that nearly 3 million people exceed the limits of sobriety in Poland every day and 4-5 million people belong to the group of heavy drinkers [19]. In comparison, in Germany, according to the German Report of Drugs and Addiction [20], more than 9 million German adults (31\% of males and $16 \%$ of females) consume inappropriate amounts of alcohol. The number of people who drink excessively, according to the findings of specialists, is proportional to the square of the increase of the average consumption. Assuming that an alcoholic usually starts a family of four, the problem of alcohol abuse in Poland may affect 20 million people.

\section{Nutritional prevention}

Similarly to our study, in the U.S. the consumers of healthy foods were mainly female, well educated, with a high income, aged 35 to 55 years [21]. Motives play a significant role in choosing health-promoting foods. According to the aforementioned study by Zunft and Friebe [22], 66\% of respondents are guided by the prevention of diseases, while a Polish study by Czapska et al. [23] showed that $74 \%$ of respondents bought this kind of foods mainly because of health benefits. Health concerns are expressed in, among other things, reduced consumption of foods rich in fat and increased fruit and vegetable consumption [24], as can be seen in the results obtained in a group of women. In the study by Szczepaniak et al. [25] on national consumers' attitudes towards healthoriented foods it was found that products with lower fat and cholesterol content have greater importance in disease prevention than those which are low in sugar and salt. Against that background, our results indicate adverse health-related food behaviours of Poles. A similar result was obtained by Pawelec [26]. The result obtained does not make us significantly different from American society. This is because U.S. consumers admittedly prefer low-calorie products which are, however, not devoid of fat [27].

These findings allow us to conclude that the knowledge of the negative impact of cholesterol on the cardiovascular system and the significance of proper nutrition does not translate into the formation of healthy eating habits. However, a change in these nutrition-related behaviours is needed. While it is true that in recent years positive changes [28] in eating behaviours of Poles, such as increased consumption of vegetables and poultry and reduced consumption of red meat, have been noted, they are still too small to constitute health-promoting behaviours [29].

As far as salt intake is concerned, along with the progress of civilization salt in the diet is becoming more common. Sodium intakes around the world are well in excess of the physiological need (i.e.
$10 \mathrm{mmol} /$ day to $20 \mathrm{mmol} /$ day). Most adult populations have mean sodium intakes $>100 \mathrm{mmol} /$ day, and for many (particularly the Asian countries) mean intakes are > $200 \mathrm{mmol} /$ day [30]. The INTERSALT study completed in 1989 [31] showed that Poland, with the average values of sodium excretion $>200$ $\mathrm{mmol} /$ day for men at the time, was next to countries such as Canada, Colombia, Hungary, India, Italy, Portugal and South Korea. Over the past 20 years a number of awareness raising activities have been undertaken in Poland to inform the public about the need to reduce the amount of sodium in the diet, which, as can be observed, yielded positive results ( $1 / 3$ of respondents declared that they limited the amount of salt in the diet, and half of the respondents indicated that they try not to overuse it). Still, taking into account the absolute values (currently $\mathrm{NaCl}$ intake in Poland amounts to $\approx 15 \mathrm{~g} / 24 \mathrm{~h}$, which exceeds three times the norm recommended by the European Society of Hypertension and the WHO set at $5 \mathrm{~g} / 24 \mathrm{~h}$ ), we are far from the level achieved in developed countries with the average daily intake of salt of $10 \mathrm{~g} / 24 \mathrm{~h}$ [32], and in American and Western Samoa [33], Spain [34], Ghana [35] and Venezuela [36], where the level of the daily intake is $<100 \mathrm{mmol}$, equivalent to $6 \mathrm{~g}$ of $\mathrm{NaCl}$.

\section{Prophylaxis in the form of physical activity}

A sedentary lifestyle constitutes one of the most important problems of the public health in developed countries. In many countries the percentage of people with too little physical activity reaches $60-70 \%$ of the adult population and at least $30-50 \%$ of children and adolescents [37]. Taking into account our results, it should be noted that Poland does not differ significantly in this respect from the above data. This is confirmed by the results of the CSO study conducted in 2008 (by the use of the Questionnaire 183-6/58.2 Special Eurobarometer. Physical Activity, 2003) comparing physical activity in Poland to the other EU countries. It shows that in Poland, $33.5 \%$ of the population reported a high level of physical activity. A higher percentage of people reported high levels of physical activity in Denmark (34.1\%), Luxembourg (36.3\%), Greece (37.0\%) and Germany (40.2\%). It should be emphasized that there was no statistically significant difference between the percentage in Poland and the European average $(31.3 \%)[3,7]$.

\section{Pharmacological prophylaxis}

Prophylactically, however, most Poles use various supplements (e.g. micronutrients, herbal preparations). Numerous studies indicate that consumption of dietary supplements is becoming increasingly 
common [39]. National research conducted by the Institute of Food and Nutrition in households in 2000 demonstrated that $20 \%$ of people [40] used supplements. Research by Pietruszka and Brzozowska proves that this phenomenon is increasing in Poland, which is also confirmed by our findings [41]. Individual use of supplements in the societies of developed countries is also common [42]. The Federation of Consumers [43] reports that in some cases sales of OTC drugs increase after each airing of advertisements, which are regarded as a reliable source of information. This trend is common in many countries $[44,45]$.

\section{Limitations}

The study was conducted in 2009. However, given the fact that behavioural changes in society proceed very slowly, it may be assumed that the results obtained do not differ much from the respective behaviours of Poles in the present year.

Moreover, no anthropometric measurements of the respondents were taken; weight and height were only reported by the subjects. Diet analysis was not based on a food diary.

In conclusion, the study presented here allowed us to analyse health-promoting behaviours of Poles undertaken to prevent HTN development. It also enabled us to draw the following conclusions: firstly, Poles take various health-promoting actions aiming to prevent HTN such as attempting to maintain normal body weight, fighting chronic stress, and reducing the intake of table salt. Secondly, in a number of other areas such as the amount and kind of alcohol consumed, cigarette smoking, physical exercise and a well-balanced diet, these actions should be considered insufficient for effective HTN prevention. Thirdly, one of the kinds of preventive actions is pharmacotherapy, which is used by approximately $30 \%$ of respondents and the most frequently used pharmaceuticals comprise dietary minerals, herbal preparations and $\omega-3$ supplements. Moreover, according to the respondents, non-pharmacological treatment is safer than pharmacological treatment, yet they also admit that the latter is more effective. Fourthly, in the group of social and demographic factors, sex is the factor that influences taking preventive actions the most. Women take prophylactic actions far more often than men.

In the face of the problems described above, it seems essential to undertake intense educational campaigns aiming to increase public awareness of the necessity and methods of preventing cardiovascular conditions, because effective HTN prophylaxis may not only improve the epidemiological situation, but also help reduce expenditure on treatment of this disease and its complications.

\section{Acknowledgments}

This work was supported by the Poznan City Hall as part of the competition for "research grants of the City of Poznan" [grant number 504-0703316440-34201-09361] to carry out a study aimed at supporting research activities in selected research areas.

\section{References}

1. Kawecka-Jaszcz K, Pośnik-Urbańska A, Jankowski P. Prevalence of arterial hypertension in Poland - impact of gender. Nad Tęt 2007; 11: 378-9.

2. Bielecka-Dabrowa A, Aronow WS, Rysz J, Banach M. The rise and fall of hypertension: lessons learned from Eastern Europe. Curr Cardiovasc Risk Rep 2011; 5: 174-9.

3. Barylski M, Małyszko J, Rysz J, Myśliwiec M, Banach M. Lipids, blood pressure, kidney - what was new in 2011? Arch Med Sci 2011; 7: 1055-66.

4. Banach M, Aronow WS. Hypertension therapy in the older adults-do we know the answers to all the questions? The status after publication of the ACCF/AHA 2011 expert consensus document on hypertension in the elderly. J Hum Hypertens 2012; 26: 641-3.

5. Cisek M, Górkiewicz M, Gniadek A, Kotarba D. Healthrelated behaviours of women from rural areas: an environmental study [Polish]. In: Professionalism in health care. Głowacka MD (ed.). WSKiZ, Swarzędz 2005; 365-76.

6. Metelska J, Nowakowska E, Kus K, Kajtowski P, Czubak A, Burda K. Evaluation of the knowledge of primary healthcare patients in Poland on the prevention of hypertension: a community study. Public Health 2011; 125: 616-25.

7. Central Statistical Office, www.stat.gov.pl, (last accessed 07 September 2010).

8. Churchil GA. Marketing research [Polish]. PWN, Warsaw 2002.

9. Mardarowicz G, Matej-Butrym A, Szcześniak G, Nicer T. Prevention of metabolic diseases of affluence in general medical practice. Part 2. Potential implementation problems [Polish]. Fam Med Prim Care Rev 2008; 10: 501-3.

10. Mastalerz-Migas A, Danecka M, Zywar K, Lubieniecki K, Muszyńska A, Steciwko A. The knowledge of healthy lifestyle principles in the families of preschoolers and its implementation in practice [Polish]. Fam Med Prim Care Rev 2009; 11: 404-6.

11. Moorman C, Matulich E. A model of consumers preventive health behaviours: the role of health motivation and health ability. J Cons Res 1993; 20: 206-28.

12. Czajkowska-Malinowska M. Epidemiological data. The influence of tobacco smoke on the respiratory system [Polish]. Pneumonol Alergol Pol 2005; 73: 5-9.

13. Zieliński J. Global burden of smoking. Pneumonol Alergol Pol 2008; 76: 170-3.

14. Zatoński W. Tobacco smoking in central European countries: Poland. In: Tobacco and public health: science and policy. Boyle P, Gray N, Henningfield J, Sefrin J, Zatoński W (eds.). Oxford University Press, London 2004; 235-52.

15. Ash. facts at a glance (2007), www.ash.org.uk (last accessed 27 December 2010).

16. European Commission. Special Eurobarometer - Report 272c: Attitudes of Europeans towards Tobacco. 2007, www.ec.europa.eu/health/ph_determinants/life_style/Tob acco/Documents/ebs272c_en.pdf (last accessed 21 December 2008). 
17. Vidya Ram. European countries with the highest alcohol consumption. 23.08.2008. www.biznes.interia.pl/news/ kraje-europy-o-najwiekszym-spozyciu-alkoholu,1164015 (last accessed 07 September 2010).

18. Egospodarka.pl, Alcohol consumption in Poland lowest in EU, http://www.egospodarka.pl/52173,Spozycie-alkoholuw-Polsce-najmniejsze-w-UE,1,39,1.html (last accessed 7 September 2010).

19. Central Statistical Office, www.stat.gov.pl (last accessed 7 September 2010).

20. Bätzing SD, Suchtbericht M. Drogenbeauftragte der Bundesregierung and Bundesministerium für Gesundheit. www.bmg.bund.de/cln 040/nn 600110/SharedDocs/Dow nload/DE/Themenschwerpunkte/Drogen-undSucht/Drogen-Suchtbericht-08,templateld=raw,property = publicationFile.pdf/Drogen-Suchtbericht-08.pdf (last accessed 21 May 2008).

21. Childs NM. Functional foods and the food industry: consumer, economic and product development issues. J Nutraceuticals, Function Medic Foods 1997; 1: 25-43.

22. Zunft HJF, Friebe D. Perceived benefits of healthy eating among a nationally-representative sample of adults in the European Union. Eur J Clinic Nutrit 1997; 51: 41-6.

23. Czapska M, Jeznach M, Święcicka A. Consumer behaviours in the functional foods market [Polish]. Handel Wewnętrzny 2002; 48: 30-3.

24. Zandstra EH, Graaf DEC, Staveren WA. Influence of health and taste attitudes on consumption of low- and high-fat foods. Food Quality and Preference 2001; 12: 75-82.

25. Szczepaniak B, Górecka D, Flaczyk E. Consumer attitudes to health-promoting food products. Żyw Człow Met 2003; 30: 1158-62.

26. Pawelec M. Feeding preferences of patients of Cardiac Surgery Department of Pomeranin Medical University. Annales Universitatis Marie Curie-Skłodowska Lublin Polonia 2005; 393: 255-9.

27. Sloan AE, Stiedmann MK. Free fat at last? Don't bet on it! Cereal Foods World 1995; 40: 803-9.

28. Babicz-Zielińska E. Food preferences among the Polish young adults. Food Quality Prefer 1999; 10: 139-45.

29. Gronowska-Senger A. Food behaviours of Poles in the light of FAO/WHO recommendations of 2003. In: Food consumers and their behaviours in Poland as a member state of the European Union. Gutkowska K, Narojek L (eds). SGGW, Warsaw 2005; 43-50.

30. Brown IJ, Tzoulaki I, Candeias V, Elliott P. Salt intakes around the world: implications for public health. Int J Epidemiol 2009; 38: 791-813.

31. Rose G, Stamler J. The INTERSALT study: background, methods and main results. INTERSALT Co-operative Research Group. J Hum Hypertens 1989; 3: 283-8.

32. Stolarz-Skrzypek K, Kawecka-Jaszcz K. Salt intake reduction as the prevention method for arterial hypertension. Postępy Nauk Medycznych 2009; 1: 34-8.

33. Galanis DJ, McGarvey ST, Quested C, Sio B, Afele-Fa'amuli SA. Dietary intake of modernizing Samoans: implications for risk of cardiovascular disease. J Am Diet Assoc 1999; 99: 184-90.

34. Schroder H, Schmelz E, Marrugat J. Relationship between diet and blood pressure in a representative Mediterranean population. Eur J Nutr 2002; 41: 161-7.

35. Cappuccio FP, Kerry SM, Micah FB, Plange-Rhule J, Eastwood JB. A community programme to reduce salt intake and blood pressure in Ghana. BMC Public Health 2006; 6: 13.

36. Negretti de Bratter VE, Bratter P, Oliver W, Alvarez N. Study of the trace element status and the dietary intake of mineral and trace elements in relation to the gastric cancer incidence in Táchira, Venezuela. In: Metal ions in biology and medicine. Collery P, Bratter P, Negretti de Bratter VE, Khassanova L, Etienne JC (eds.). John Libbet Eurotext, Paris 1998; 557-65.

37. Drygas W, Jagier A. Physical exercise recommendations in the prevention of cardiovascular diseases [Polish]. Czyn Ryz 2002/2003; 38/39: 76-84.

38. Sjöström M, Oja P, Hagströmer M, Smith BJ, Bauman A. Health-enhancing physical activity across European Union countries: the Eurobarometer study. J Public Health 2006; 14: 291-300.

39. Kunachowicz H, Troszczyńska A. Fortified foods and vitamin/mineral supplements and their role in proper nutrition [Polish]. Now Lek 2005; 74: 533-8.

40. Szponar L, Stoś K, Ołtarzewski M. Dietary supplements: possibilities of use in the prevention of selected nutritional deficiencies [Polish]. Żyw Człow Metab 2004; 31: 441-6.

41. Pietruszka B, Brzozowska A. Determinants of vitamin and mineral supplementation in Poland [Polish]. Żyw Człow Metab 2002; 29: 215-9.

42. American Dietetic Association. Practice paper of the American Dietetic Association: Dietary supplements. J Am Diet Assoc 2005; 105: 460-70.

43. Federation of Consumers. Advertisement of medicines, pseudo-drugs and vitamin supplements], http://www. federacja-konsumentow.org.pl/story.php?story=133 (last accessed 26 August 2010) according to Czasopismo Aptekarskie 2002; 12/98: 584.

44. Perii M, Dickson WM. Direct to consumer prescription drug advertising: consumer attitudes and physician reaction. Journal of Pharmaceutical Marketing and Management 1987; 3350: 3-25.

45. Mintzes B, Barer ML, Kravitz RL, et al. Influence of direct to consumer pharmaceutical advertising and patients' requests on prescribing decisions: two sites cross sectional survey. Br Med J 2002; 21270: 278-9. 